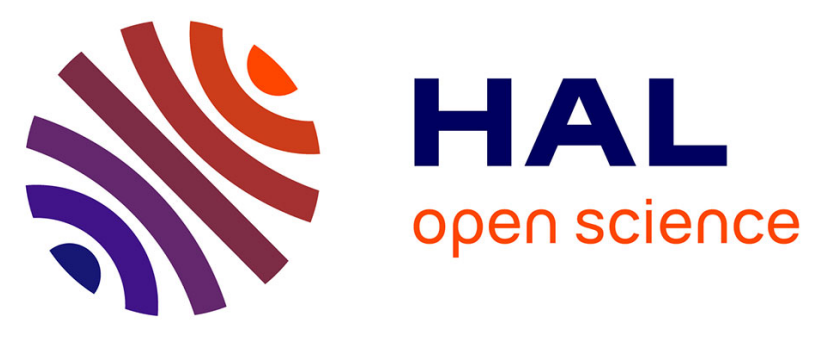

\title{
Research in Progress: Holistic Climate Service Prototypes for Farmers in Tambuu, Tanzania
}

Ville Myllynpää, Jaakko Helminen, Ezra Misaki, Mikko Apiola, Jani Haakana, Tomi Westerlund, Erkki Sutinen

\section{- To cite this version:}

Ville Myllynpää, Jaakko Helminen, Ezra Misaki, Mikko Apiola, Jani Haakana, et al.. Research in Progress: Holistic Climate Service Prototypes for Farmers in Tambuu, Tanzania. 15th International Conference on Social Implications of Computers in Developing Countries (ICT4D), May 2019, Dar es Salaam, Tanzania. pp.294-302, 10.1007/978-3-030-19115-3_24 . hal-02281301

\section{HAL Id: hal-02281301 \\ https://hal.inria.fr/hal-02281301}

Submitted on 9 Sep 2019

HAL is a multi-disciplinary open access archive for the deposit and dissemination of scientific research documents, whether they are published or not. The documents may come from teaching and research institutions in France or abroad, or from public or private research centers.
L'archive ouverte pluridisciplinaire HAL, est destinée au dépôt et à la diffusion de documents scientifiques de niveau recherche, publiés ou non, émanant des établissements d'enseignement et de recherche français ou étrangers, des laboratoires publics ou privés. 


\title{
Research in Progress: Holistic Climate Service Prototypes for Farmers in Tambuu, Tanzania
}

\author{
Ville Myllynpää ${ }^{1}$, Jaakko Helminen ${ }^{1}$, Ezra Misaki ${ }^{2}$, Mikko Apiola ${ }^{1}$, \\ Haakana $^{1}$, Tomi Westerlund ${ }^{1}$ and Erkki Sutinen ${ }^{1}$ \\ Jani \\ ${ }^{1}$ University of Turku, Turku, Finland \\ firstname. lastnamedu- \\ tu.fi \\ ${ }^{2}$ College of Business Education (CBE), Dar es Salaam, Tanzania \\ e.misak- \\ i@cbe.ac.tz
}

\begin{abstract}
Urgent efforts are needed to address climate change and changing climate variability. Solutions are needed at economic, political, scientific, educational, as well as technological domains. Our previous research in Tambuu, Tanzania, shows that the acute information needs of the community are credible and trustworthy weather information, knowledge in best uses of weather information, and education about best farming practices. Delivering the information for end users in Tambuu is a challenge in itself. Based on these results and following the principles of System Action Design Research, we developed prototypes for future climate services together with local farmers in Tambuu community. These prototypes and our future plans are presented in this research-in-progress paper.
\end{abstract}

Keywords: System Action Design Research, Climate services, Climate change, Mobile technology

\section{Introduction}

Climate change is one of the most serious problems of the world today. Climate change may cause uncontrolled sequences of fatal harms, and it directly threatens the future existence of humankind. The negative effects of climate change are already being experienced globally, but particularly in the Global South, mainly by the most vulnerable groups of people. Therefore actions need to be urgently taken in order to adapt to changing climate conditions.

This paper reports second phase of our project, which initiated climate service prototype development. This work is based on results of our previous research about needs and priorities of Tambuu community, Tanzania [14]. These developed climate services would assist smallholder farmers in adapting to climate change, and will help steer their development in a sustainable direction.

\section{Previous and related research}


Our previous research [14] shows that the farmers in Tambuu village have experienced the impacts of climate change. The farmers' experiences of changing climate patterns were found to be well aligned with measurements done by the Tanzanian Meteorological Agency (TMA) [14]. Research shows that scenarios for future rainfall vary a lot [17]. The only certain thing is that uncertainty about amount, duration, and timing of rain will increase [14]. In addition to climate related acute information needs, several other information needs were also found, including information about agricultural practices and training to use them properly. The current sources for information were found to be often unreliable [14]. The information needs in Tambuu are sum up in Table 1.

Table 1. Information needs of Tambuu villagers [14]

\section{Acute information and other needs}

Credible and trustworthy weather information

Knowledge in best uses of weather information

Education about best farming practices

Farming inputs (seeds, fertilizers, equipment)

Soil management tips and soil testing service

Financial services and marketing skills

In regards of the current mobile phone usage patterns, voice calls, short messages, calendar, and clock were the most popular applications [14]. Some "modern" uses were also found, when, for example, farmers took photos of insects and sent them for analysis to a relative [14]. Smartphone ownership was found to be low. Without electricity coverage in Tambuu, charging of mobile devices was done with the help of generators or solar panels [14]. A number of related challenges were revealed. These included weak network coverage, low technical competence, high prices of mobile usage and phones, usability issues of smartphones, especially relating to the touchscreen, and English language [14].

A number of projects have attempted to use mobile technology to provide farmers in developing countries with services such as weather information, market data, agronomy tips, crop information, and various others [11, 9, 10]. Common examples of those approaches include market information and market place service M-Farm ${ }^{1}$, and Airtel Kilimo ${ }^{2}$, which provides farmers with agricultural information, weather forecasts, and market information. Many other services are still in testing and development phase, with little proven positive impacts to farmers' activities [11].

Many current climate services projects have been launched for instance in Tanzania, Kenya and Uganda, from which learnings about the suitable content for climate services can be adopted. In Tanzania, project operating under Global Framework of Climate Services was using participatory methods to train intermediates, which would

https://www.mfarm.co

ke

https://www.gsma.com/mobilefordevelopment/programme/magri/airt el-kilimoproject-update-insights-from-the-midline/ 
Research in Progress: Holistic Climate Service Prototypes for Farmers in Tambuu, Tanzania 3

spread climate information to rural farmers ${ }^{3}$. In Uganda, a project called Climate Change Adaptation and ICT (CHAI) reached 120000 farmers, which receive weather forecasts and locally tailored agricultural advisories by SMS. It collected weather data from 22 sub-country weather station, as well as crop and livestock market information from 46 market places ${ }^{4}$. Project in Kenya provides evidence about the impact of these climate services by revealing that farmers, which received climate information were better in crop management and got also higher yields, as compared to farmers in the control group [16].

Generally well suited rules relating to the content of these mobile services for small scale farmers include following points; 1) Information must be relevant, timely and actionable by the farmers [1], 2) Information should be disseminated based on the crop cycle 3) Information should be breaking down into comprehensive pieces for farmers to understand 4) Use of information intermediates could be a one solution in spreading complex information to farmers [2].

In terms of technical qualifications of the app, the past literature has identified following well tried and tested design principles for mobile services in developing countries; 1) Understand users and their needs [1], 2) Use participatory design, 3) Identify suitable partners, 4) Develop viable business model and 5) Monitor and evaluate the progress $[4,2]$.

In Tambuu, we found that the mobile infrastructure is decent, however, mobile internet connectivity was relatively weak. Many small scale farmers in Tambuu, and in Tanzania, do not, at the present moment, have smartphones. Designing applications, especially ones delivering weather and climate related information, for USSD is difficult, due to its technical limitations in terms of presenting visual elements and cumbersome navigation between different menus [1]. Second, estimates show that smartphone ownership is increasing in emerging economies (e.g. [15]), which makes them a potent platform for future applications.

\section{System Action Design Research}

The situation calls for a resilient and iterative design research methodology. First, functioning of crucial systems change constantly. These systems include cultivation practices, agricultural education, technology in local communities, climate, and climate variability. To address the needed resilience and agility in this project, we use the System Action Design Research framework (SADR) and Epistemic Implementation Delphi model (EID) [6] in project implementation. SADR is an extension to Design Science Research (DSR) [8, 13]. EID is a scientific model for project implementation that is based on building a mutual agreement between stakeholders [6]. DSR is different from "routine design", where existing knowledge is applied to solve problems by using "best practice” knowledge and theory [7]. In

\footnotetext{
3 https://www.wfp.org/stories/climate-services-farmerstanzania

4 https://www.fhi360.org/projects/climate-change-adaptationand-ict-chai
} 
SADR and EID, rigorous research methodology is brought to back up the design process in situations, where the end-user demands, contextual and sociocultural factors, and many other important issues in the design process are not understood well enough to use a linear design process [6]. SADR and EID are specifically designed to fit well into the developing country contexts [6].

\section{Approach}

The design activities were conducted in Tambuu village. The later part of the activities consisted of a technology prototype workshop, to which total of eight farmers participated. These farmers represented various ages and educational and mobile literacy levels. Four of the participating farmers were interviewed (Group 1) during previous days of primary data collection [14], and four were not (Group 2). Group 1 consisted of three males and one female (average age 41, $\min =23 \max =58$ ) and Group 2 consisted of three females and one male (average age 47, min=43 $\max =58$ ). Aim of the workshops was to introduce our first technology prototype for the participants, and to get their first impressions about using it.

In addition, the workshop contained a session about weather icons. Several weather-related icons were presented and the farmers' viewpoints to those icons were asked. This was followed by an icon-design experiment, where the participants and researchers designed icons for few weather related situations, such as drought and floods and few agricultural related actions such as planting, weeding, and harvesting. This workshop was led by local researchers in ki-Swahili, assisted by other researchers by drawing icons into flipcharts based on the farmers' ideas and comments.

We used the examples of Sapelli project [18], where icons and interfaces where designed for application aimed for collecting traditional ecological knowledge by nonliterate forest people in Congolese rainforest, and Street vendor's project [12], where icons were designed for bookkeeping application aimed to street vendors in Dar es Salaam, Tanzania, as a source of ideas and inspiration when planning the activities of this workshop.

\section{$5 \quad$ Technology prototypes}

To address the information needs of Tambuu community, we came up with a number of possible ideas for future technology solutions, as a result of the interviews and workshops as well as the prior literature research phase. In Table 2, ideas for future applications are listed. Due to its major importance, the main focus of this project is with weather and decision making tools that help farmers in adapting to the changing climate. However, farmers needs in terms of information about best farming practices, access to seed and market data, financial services, and soil management, need to be crucially addressed too. 
Table 2. Technology solutions for Tambuu

\begin{tabular}{|l|}
\hline \multicolumn{1}{|c|}{ Future mobile solutions for Tambuu } \\
\hline Credible weather information services \\
Farming decision making tools \\
Educational applications for best farming practices \\
Trusted market for farming inputs \\
Financial services and marketing technology \\
Soil management and soil testing application \\
Information exchange applications \\
\hline
\end{tabular}

\subsection{First prototype}

During the workshops, it was found out that the villagers were very knowledgeable about the local effects of climate change and they were interested in credible weather predictions and forecasts in relation to the whole growing season. In addition, specific farming knowledge in regards of different plants was found to be of high interest. The three primary information needs in regards of climate are as follows: 1) long-term seasonal weather predictions, 2) short-term weather predictions, and 3) common knowledge about effective farming practices. This observation is also mentioned in one prior article covering farmer's information needs in Tanzania [3], which also pointed out the special importance of information about the starting point of the rains, expected rainfall of the season and end of the rains for the farmers. Since reading and writing skills were found to be at a reasonable level, we decided to include both a picture and text for each navigation element and icon. This was intended to reduce the required cognitive workload and make the correct functionality easier to find.

In developing a climate service application, three problems need to be addressed. First, credible weather data needs to be acquired, together with supportive agricultural and other information. Second, that weather and agricultural data needs to be algorithmically processed. Third, the processed data needs to be presented to endusers. The following sections will give our ideas about how to address these problems.

\subsection{Sources and access to data}

In order to develop a mobile climate service, climate and weather, as well as other supportive data needs to be acquired. The source of climate and weather data can range from local or international meteorological agencies, NGOs, universities and research institutions, to data from sensors such as local weather stations or soil moisture measurements, or data collected by mobile devices from farmers themselves. A number of agriculture related content platforms have been launched, including Toto 
Agriculture $^{5}$ which is dedicated to sharing agricultural information in actionable formats.

In regards of Tambuu, the local Sokoine University of Agriculture (SUA) has an impressive repository of research-based farming information, which is one important source for supportive agricultural data. Then, one crucial question is, how to automatically process that data, which is currently in the form of reports, theses, journal articles, raw statistical data, and pamphlets, into data that can be used to give concrete suggestions for farmers in their decision making.

\subsection{Algorithmic processing of data}

After the data is obtained from the data sources, such as international or local information services, or from repositories such as SUA's research repository, the data needs to be algorithmically processed before it can be presented to an end user. This design process, which needs to be done in collaboration with different stakeholders, using statistical methods, big data processing methods, machine learning, and natural language processing (NLP) methods need to be creatively applied to write sophisticated and contextually relevant data processing algorithms. All available components and suitable algorithms for processing weather and climate data must be used in order to avoid reinventing something that has already been invented.

\subsection{Presenting the data (User interface)}

In the first prototype experiments, which were conducted together with the farmers of Tambuu, we started with the assumption that all possible climate and weather, as well as other required data is available. The first mobile user interface prototype was created beforehand for Android-platform which is the most common mobile platform in many developing countries. In the user interface design, material design [5] was used. The first prototype application was designed by using Google's Flutter-library ${ }^{6}$. In Fig. 1 we show the very first prototype of the user interface for the application as an English language version. During the session used ki-Swahili language version.

\subsection{Icon design experiments}

In the beginning of the second activity, we presented the farmers with commonly used weather icons and they were instructed on what each of them meant. They were also asked, whether they considered the symbols self-explanatory, meaning did the symbols make sense to them initially, or did they require explanation. This part revealed that some elements of the symbols, such as lack of ground level and shape of the clouds where confusing for the locals. To overcome this challenge, we plan to

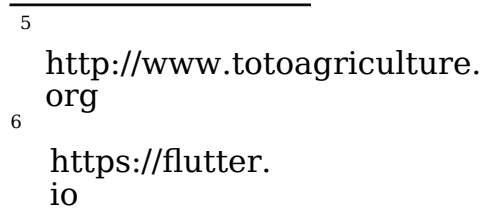


Research in Progress: Holistic Climate Service Prototypes for Farmers in Tambuu, Tanzania 7

implement explanation-menu into the final app prototype, where weather icons are explained in simple terms. Finally the study participants were given a task of codesigning an icon for flood and drought conditions.

Originally we were also thinking of re-designing the common weather symbols, but decided to drop that idea since those are so commonly used by other weather service outlets, such as newspapers, TV and other apps, that remaking them would probably

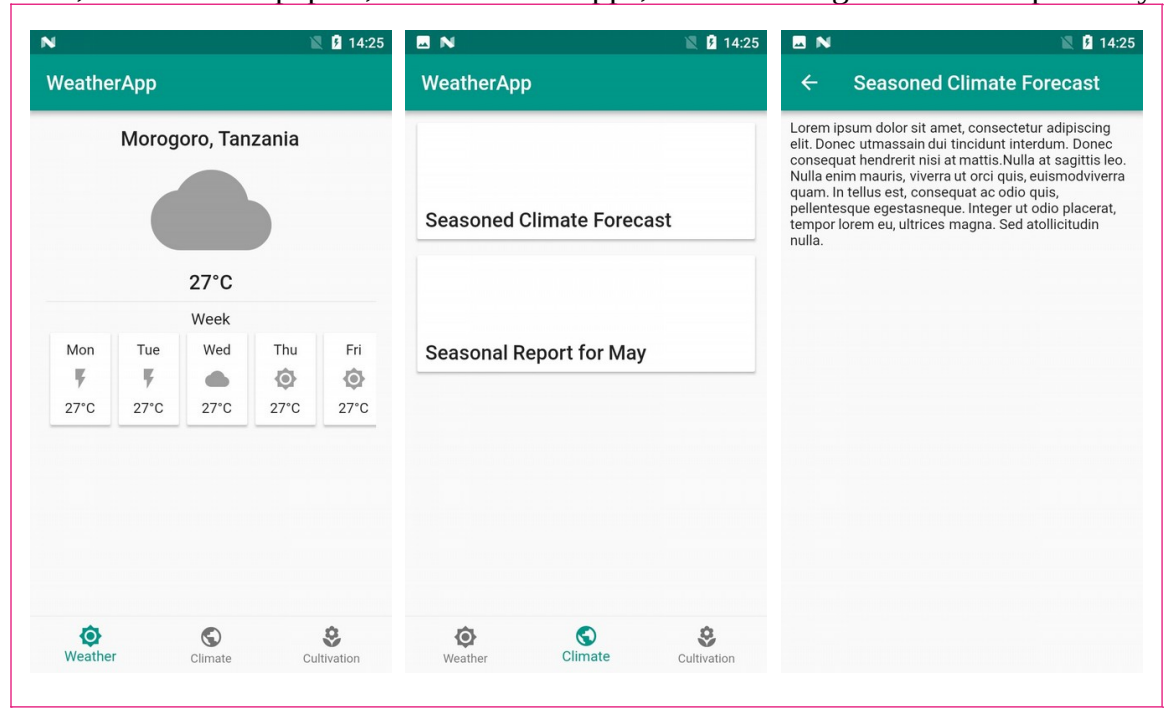

Fig.1. Screenshots of the first prototype. From left to right: short term weather forecast, menu selection and seasonal climate forecast.

just confuse users. Icon design sessions started with the researcher explaining the idea of the session and the category for the icon in question. Sessions were led by our local researcher in Swahili, assisted by other researchers, who were drawing the icons into flipcharts, based on the farmer's comments. As a final part, participants were instructed to design icons for planting, weeding and harvesting actions, following the same procedure as with weather icons.

The reason why we focused on icons, both the weather related and farming related, was that they were something tangible, something to which farmers can connect their farm activities and therefore are able to give ideas, for example, on how the planting icon could look like. This method was estimated to be the most functional way to get farmers to participate into the design process and build ownership to the app at this point. All the session where successful, and participants willingly and openly expressed their opinions and ideas, as well as ask questions from the researchers. 


\section{Conclusions}

The design of the future climate technologies is a challenging task, but an interesting and inspiring one, too. This task requires experts from multiple fields, for example, meteorological, statistical, computational, human computer interaction (HCI), and interaction design (IxD) skills are crucially required. Technology initiatives cannot solve big problems alone, but they must work in collaboration with other development efforts and initiatives. Thus, participatory design, which means involving all stakeholders and especially the end-users in the design process as equal members, is of utmost importance.

There are three specific information needs in Tambuu community: short-term weather predictions, long-term weather predictions, and common knowledge about effective farming practices. Therefore, we will take a holistic view to the climate services, and we will include also the short term weather forecast and general agricultural information to the app. Short term weather information will allow farmers to make detailed decision on when to start planting. General agricultural information, for instance about Climate-Smart Agriculture (CSA), helps farmers to adapt and prepare for the changing climate conditions in their farms.

We are addressing this design problem from three fronts: by exploring the reliable sources of data, by algorithmically processing the data, and by designing contextually relevant user interfaces. In regards of user interface (UI) design, the future steps include designing various options to present additional information in the app. Then, when our researchers visit Tambuu next time, they would present those different UI design options to local farmers and would integrate them into the process of selecting and fine-tuning the most suitable UI elements. During this phase, other feedback, about such topic as suitable content and features, is also collected, in order to build the final version of the app.

Besides the importance of UI design, we will have few other guiding principles for the technical development of this climate service. Firstly, the final app design will be optimized in terms of its data usage, meaning in practices that after the initial installation, the future updates and other data transfers are kept in minimum, so to guarantee that apps usage doesn't create a too big data bill for its users and cause then to stop using the service. Secondly, we will focus on the user privacy, by keeping all the data in secured servers and when analysing the user data, it will be done anonymously, so that the individual users cannot be recognized from the data.

Final version of the app will be used in the actual field testing phase, which has the aim of verifying apps benefits by comparing app users to farmers without access to information. We acknowledge that the icon design is only a small part of the whole app design, but aim of this exercise was mostly to find out how the co-design sessions can be held in the village, e.g., what type of interaction and explanation works there, in order to prepare the team for the next phases of the development process.

This app is not, naturally, going to be any "silver-bullet" that will solve all the issues among the farmers and that is a reason why we also emphasize the need for improving the access to physical farm inputs (such as improved seeds and fertilizers) and improvements in road network and electrical grid coverage, among other aspects. 
Research in Progress: Holistic Climate Service Prototypes for Farmers in Tambuu, Tanzania 9

\section{References}

1. Aker, J. C., Ghosh, I., Burrell, J.: The promise (and pitfalls) of ICT for agriculture initiatives. Agricultural Economics 47(S1) (2016)

2. Caine, A., Clarke, A., Clarkson, G., Dorward, P.: Mobile phone applications for weather and climate information for smallholder farmer decision making. Digital Technologies for Agricultural and Rural Development in the Global South (ed. R. Duncombe) (2018)

3. Coulibaly, Y., Kundhlande, G., Amosi, N., Tall, A., Kaur, H., Hansen, J.: What climate services do farmers and pastoralists need in Tanzania? Baseline study for the GFCS adaptation program in Africa. CCAFS Working Paper no. 110. Copenhagen, Denmark: CGIAR Research Program on Climate Change, Agriculture and Food Security (CCAFS) (2015)

4. Donovan, K.: Anytime, Anywhere: Mobile Devices and Services and Their Impact on Agriculture and Rural Development (2017)

5. Google: Google Material Design, https://material.io/design/

6. Helminen, J., Myllynpää, V., Apiola, M., Dayoub, M., Westerlund, T., Sutinen, E.: Community climate services for small-scale farmers in Tanzania. In: 2018 IST-Africa Week Conference (IST-Africa). (2018)

7. Hevner, A., Chatterjee, S.: Design Science Research in Information Systems. Springer US, Boston, MA (2010). https://doi.org/10.1007/978-1-4419-5653-8 2

8. Hevner, A., Salvatore, M., Jinsoo, P., Sudha, R.: Design science in information systems research. MIS Quarterly 28(1) (2004)

9. Misaki, E., Apiola, M., Gaiani, S.: Technology for Agriculture: Information Channels for Decision Making in Chamwino, Tanzania. In: Proceedings 21st ICE/IEEE Int. Technology Management Conference. Belfast, Northern Ireland (2015)

10. Misaki, E., Apiola, M., Gaiani, S.: Technology for Small Scale Farmers in Tanzania: A Design Science Approach. Electronic Journal of Information Systems in Developing Countries 74(4) (2016)

11. Misaki, E., Apiola, M., Gaiani, S., Tedre, M.: Challenges facing sub-Saharan small scale farmers in accessing farming information through mobile phones: A systematic literature review. The Electronic Journal of Information Systems in Developing Countries 84(4) (2018). https://doi.org/10.1002/isd2.12034

12. Mramba, N., Tulilahti, J., Apiola, M.: Bookkeeping for Informal Workers: Co-creating with Street Traders. Springer International Publishing, Cham (2016)

13. Mullarkey, M. T., Hevner, A. R.: An elaborated action design research process model. European Journal of Information Systems (2018).

14. Myllynpää, V., Misaki, E., Apiola, M., Helminen, J., Dayoub, M., Westerlund, T.,

Sutinen, E.: Towards Holistic Mobile Climate Services for Farmers in Tambuu, Tanzania. In: To Appear in Proceedings of IFIP WG 9.4 The 15th International Conference on Social Implications of Computers in Developing Countries. Dar es Salaam, Tanzania (2019)

15. Poushter, J.: Smartphone Ownership and Internet Usage Continues to Climb in Emerging Economies (2016)

16. Rao, K., Hansen, J., Njiru, E., Githungo, W., Oyoo, A.: Impacts of seasonal climate communication strategies on farm management and livelihoods in Wote, Kenya. CGIAR Research Program on Climate Change, Agriculture and Food Security (CCAFS) / CCAFS Working Paper no 137 (2015)

17. Tanzania Ministry of Agriculture, Food Security and Cooperatives: Agriculture Climate Resilience Plan 2014-2019. Government of Tanzania (2014) 
10 Myllynpää et al.

18. Vitos, M., Altenbuchner, J., Stevens, M., Conquest, G., Lewis, J., Haklay, M.: Supporting collaboration with non-literate forest communities in the Congo-basin (2017). https:// doi.org/10.1145/2998181.2998242 